\title{
Reduction Mammoplasty Approach to Oncoplasty- Zone-Wise Planning in Indian Patients
}

\author{
Vinay Kant Shankhdhar ${ }^{1}$ Dushyant Jaiswal ${ }^{1} \quad$ Chirag Bhansali ${ }^{1} \quad$ Rupak Despande $^{1}$ \\ Prabha S. Yadav ${ }^{1}$ Saumya Mathews ${ }^{1}$ Mayur Mantri ${ }^{1}$ \\ ${ }^{1}$ Department of Plastic and Reconstructive Surgery, Tata Memorial \\ Centre, Homi Bhabha National Institute, Mumbai, Maharashtra, \\ India

\begin{abstract}
Address for correspondence Dr. Vinay Kant Shankhdhar, MCh, Department of Plastic and Reconstructive Surgery, Room No. 1210, 12th Floor, Homi Bhabha Block, Tata Memorial Hospital, Dr. Earnest Borges Marg, Parel, Mumbai 400012, Maharashtra, India
\end{abstract} \\ (e-mail: vinayshankhdhar@gmail.com).
}

Indian J Plast Surg 2021;54:264-271.
Abstract

Keywords

- breast conservation surgery reconstruction

- breast oncoplasty

- zone-wise planning

- reduction mammoplasty
Introduction This article is an attempt to formulate certain guidelines for planning of zone-wise reconstruction after breast conservation surgery. The planning involves applying reduction mammoplasty principles with certain modifications to address the defect.

Patients and Methods This is a retrospective study of 61 patients with breast cancer who underwent breast conservation surgery and reconstruction of partial breast defects with oncoplastic techniques between January 2014 to March 2019. Patients having low tumor to breast ratio and thus good candidates for volume displacement techniques were included in the study.

Results A total of 61 breast cancer cases were included; 22 cases were located in zone 1 , nine in zone 2 , seven in zone 3 , three in zone 4 , four in zone 5 , one in zone 6 , 12 in zone 7 , two in zone 8 , and three in zone 9 . The most common pedicle design used was superomedial in 38 cases, followed by inferior in 19 and medial in 6 cases. Vertical short scar technique was used in 33 cases and Wise pattern skin incision in 30 cases. Follow-up period ranged from 4 months to 65 months, with a mean of 31 months. Four patients had partial skin necrosis, three had suture line dehiscence, two had wound infection, one had seroma, and eight patients had fat necrosis. All patients were satisfied with the cosmetic outcome.

Conclusion Breast oncoplastic techniques are effective, reliable, oncologically safe, and conducted with minimal complications in patients with moderately large ptotic breasts, thereby making planning easier and more reproducible by following the reconstruction procedures described in the article. We believe that these techniques should be incorporated in the armamentarium of every plastic surgeon to manage the defects created after breast conservation surgery, in order to achieve the best cosmetic outcomes. published online September 13, 2021
DOI https://doi.org/

$10.1055 / \mathrm{s}-0041-1735426$ ISSN 0970-0358
(C) 2021. Association of Plastic Surgeons of India.

This is an open access article published by Thieme under the terms of the Creative Commons Attribution-NonDerivative-NonCommercial-License, permitting copying and reproduction so long as the original work is given appropriate credit. Contents may not be used for commercial purposes, or adapted, remixed, transformed or built upon. (https://creativecommons.org/licenses/by-nc-nd/4.0/).

Thieme Medical and Scientific Publishers Pvt. Ltd. A-12, 2nd Floor, Sector 2, Noida-201301 UP, India 


\section{Introduction}

The load of breast cancer among Indian females with age adjusted rate is as high as 25.8 per 100,000 women. ${ }^{1}$ Over the last decade, there has been a quantum change in the management of breast cancer afforded by advanced diagnostic modalities and effective adjuvant therapy. One of the most important aspects being the change in the surgical approach from radical mastectomies to breast conservation surgery due to increased patient awareness, sensitive diagnostic tests, and the use of neoadjuvant chemotherapy.

Breast conservation therapy (BCT) consists of wide local excision with or without axillary clearance, accompanied by postoperative radiotherapy, with the recurrence rates comparable to mastectomy. ${ }^{2,3}$ While primary closure is possible in all BCT defects, it is not the best option with regard to aesthesis. The position of nipple-areola complex (NAC) and shape of the breast as well as maintenance of bilateral symmetry are key to providing an aesthetic breast reconstruction.

Oncoplastic breast surgery applies plastic surgery principles to help maintain the breast contour, using the residual breast tissue. Immediate breast reconstruction using oncoplastic principles can be done with the help of volume displacement and volume replacement techniques. ${ }^{4}$

Volume displacement techniques rearrange adjacent residual breast tissues into the defect to maintain the breast contour, while volume replacement techniques use the tissues distant from the breast. Both the procedures can be combined with volume symmetrization technique of the opposite breast for better aesthetic results.

\section{Relevant Clinical Anatomy}

In-depth knowledge of the blood supply of breast, especially of the NAC, is a prerequisite before performing breast oncoplastic surgeries. Breast is supplied by musculocutaneous perforators from the internal mammary vessels and the intercostal vessels. These larger vessels, which are arranged radially around the NAC, ultimately terminate in the subdermal plexus. These vessels provide the vascular basis of the dermoglandular flaps, commonly employed while performing the oncoplastic surgeries. Vascular basis of the various available dermoglandular pedicles is summarized in - Fig. $\mathbf{1}$.

This article is an attempt to formulate certain guidelines for the planning of zone-wise reconstruction after BCT. The planning involves applying various reduction mammoplasty principles with certain modifications to address the defect. The major considerations being the position of the NAC, breast shape, and symmetry. Thus, the tissue that is generally discarded is also utilized to achieve the shape as well as the symmetry of the breast.

\section{Patients and Methods}

This is a retrospective study of 61 breast cancer patients who underwent breast conservation surgery and subsequent reconstruction of their partial breast defects with oncoplastic techniques at our institute between January 2014 to
March 2019. Patients having low tumor to breast ratio and thus good candidates for volume displacement techniques were included in the study. The oncological safety of the procedure planned was assessed and ensured in the breast disease management group joint clinic.

The mean age was 46.7 years (range 33 to 64 years). The tumor node metastasis (TNM) staging was as follows:

$$
\begin{gathered}
\mathrm{Tx}=15, \mathrm{~T} 1=10, \mathrm{~T} 2=23, \mathrm{~T} 3=11, \mathrm{~T} 4 \mathrm{~b}=2 . \\
\mathrm{N} 0=33, \mathrm{~N} 1=25, \mathrm{~N} 2=3 .
\end{gathered}
$$

All patients having distant metastasis and requiring local/distant flaps for reconstruction were excluded.

The excision of the breast was done by the breast surgeons; they confirmed that the skin was only removed in cases where it was involved, or its removal was required for oncological safety.

Opposite symmetrization procedure was performed in all patients after obtaining proper informed consent. All patients were discharged on the next day of the surgery, with the drains in situ, and subsequently asked to follow-up on alternate days till suture removal. Drains were removed after the drain output was less than 15 to $20 \mathrm{~mL}$. All the patients were asked about the outcome on follow-up. Data of all the patients were entered in an Excel sheet and analyzed.

\section{Surgical Technique}

The basic principle used in volume displacement methods is also used for reduction mammoplasty techniques. In reduction mammoplasty techniques, some tissue is excised to reduce the breast volume, while the remaining tissue is readjusted to reposition the NAC in a more desirable location. This results in the correction of ptosis and volume reduction while improving the contour of the breast, all at the same time. The NAC is based on dermo-glandular pedicles which are, in turn, based on the musculocutaneous perforators of the internal mammary and the intercostals arteries.

A minimum of two pedicle techniques, namely, the superomedial and inferior pedicle are required to address the majority of the defects. The breast tissue is divided into nine zones for planning, a rational modification of Kronowitz's et al concept of zones (-Fig. 2). These zones have been divided for the sake of understanding and tumors often lie across zones. Thus, some deviation from the recommended techniques may be required for tumors at the junction of zones.

\section{Zone 7,8 and 9 (-Fig. 3 )}

These are the zones that lie in the part of the breast parenchyma excised as a part of the standard superomedial reduction mammoplasty procedure. Thus, at the end of the procedure, the tumor is excised as part of the tissue excised for the reduction procedure, and the breast is rearranged to give a normal contour. Involving the breast surgeon during the marking of the skin excision is important. The nipple-areola position is readjusted. This is the ideal situation where the modification of the standard reduction mammoplasty technique is not required.

As the tumor excision may lie in different zones of the breast, we need to alter the planning.

$$
\text { Zone1 (-Fig. 4) }
$$




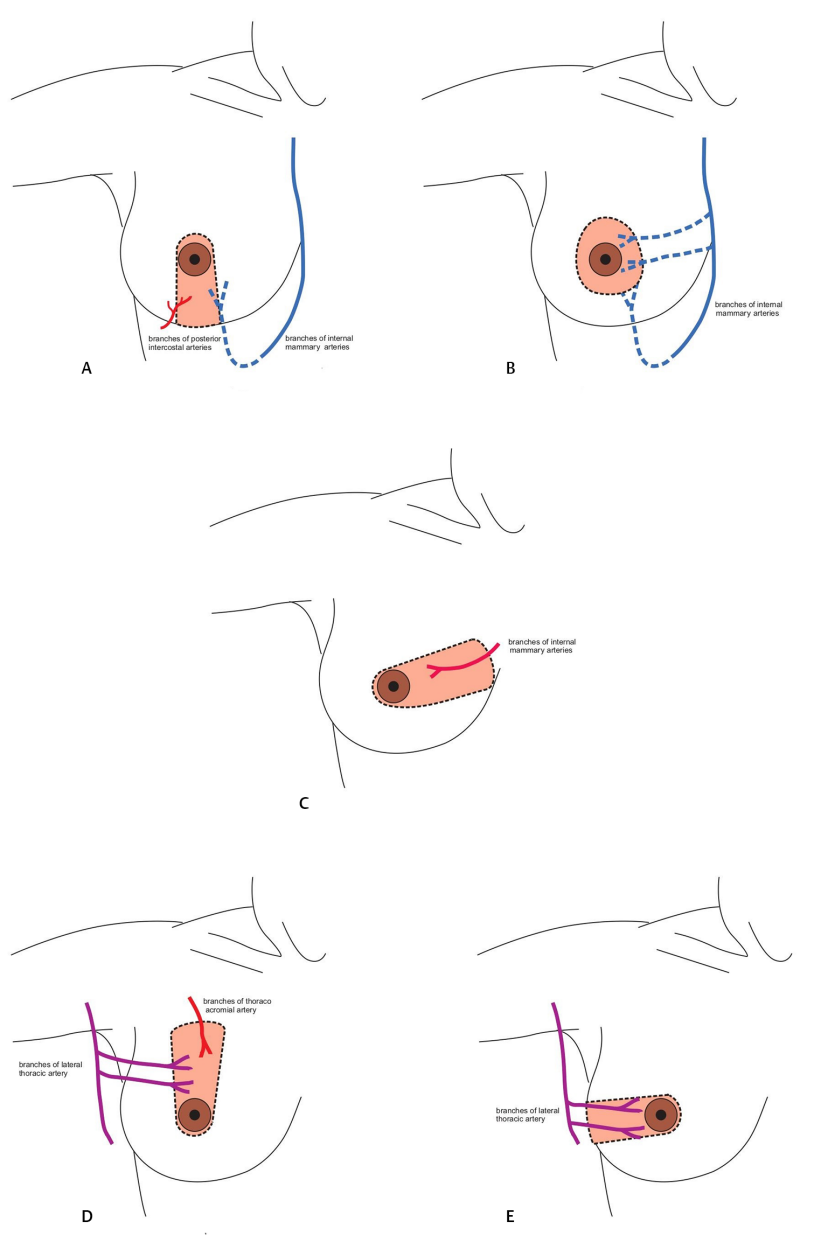

Fig. 1 Arterial anatomy of dermoglandular nipple-areola complex (NAC) pedicles. (a) Inferior pedicle. (b) Central pedicle. (c) Medial pedicle. (d) Superior pedicle. (e) Lateral pedicle.

The defect lies in the upper outer quadrant. The defect may be small; in which case, it has to be addressed by primary closure, and reduction mammoplasty is planned separately.

In very large breasts where massive reduction is planned, inferior pedicle reduction can be planned, in which most of the tissue in upper outer quadrant along with the tumor is excised, and the breast is made up of only breast tissue in the inferior pedicle.

If the cavity is large and requires additional tissue, then a lateral based flap may be transposed in to fill the cavity ( - Fig. 4a-f).

If, however, the skin is to be removed over the tumor, it is preferable to put the incision in the anatomical lines and take an extended pedicle with an oval or elliptical skin island, in order to replace the lost skin, which will heal better (-Fig. 4f-k).

Zone 2 (-Fig. 5)

The defect lies above the position of the new NAC.

Both the superomedial and inferior pedicle techniques are possible, as the resulting defect would not violate the

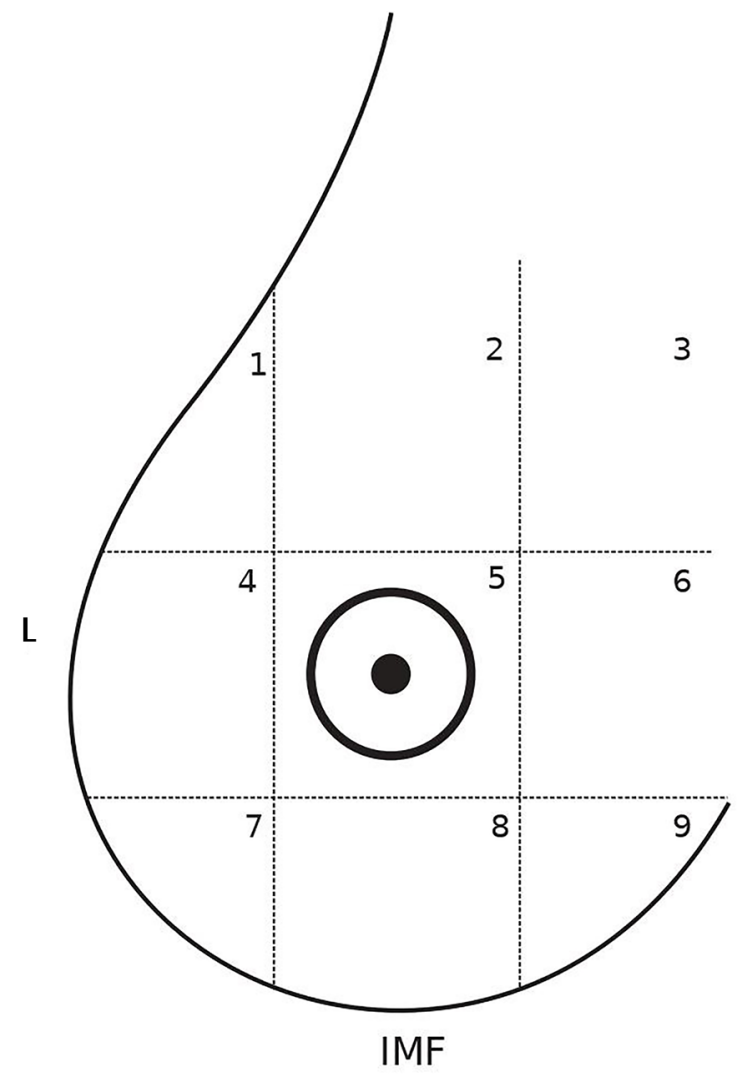

M

Fig. 2 Zones of breast.
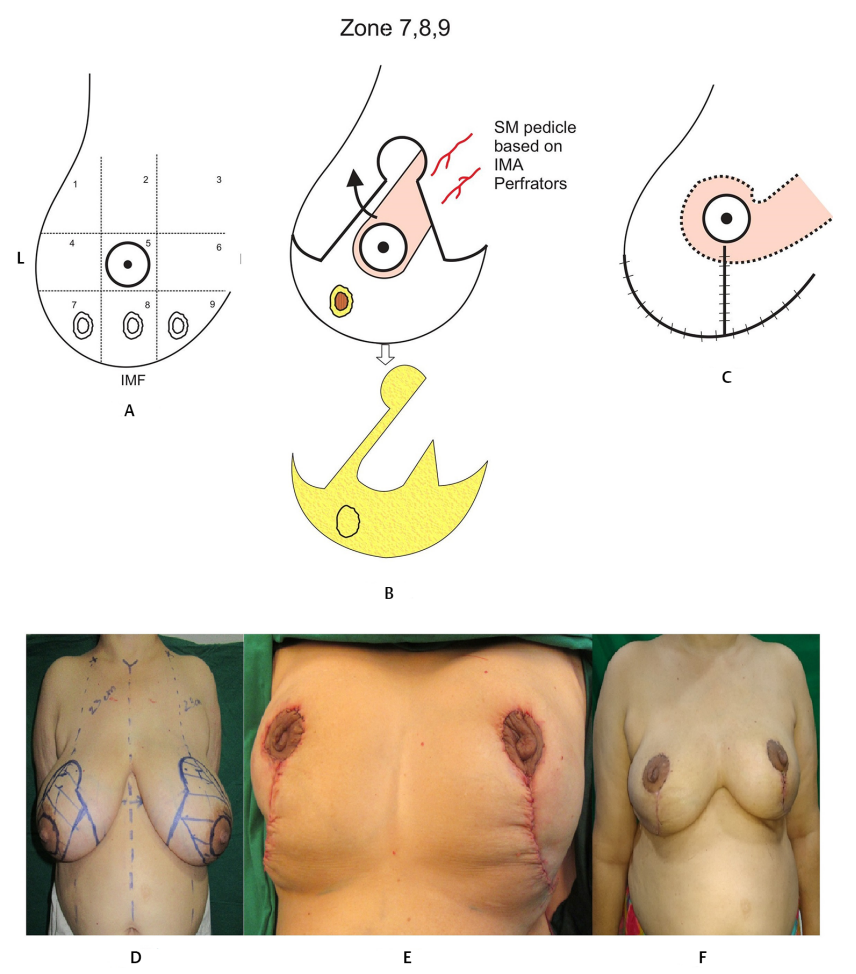

Fig. 3 Operative technique and clinical photographs for management of defects in zones 7, 8, 9. (a) Defect location. (b)Tumour tissue excised in breast reduction mammoplasty tissue (Wise pattern). (c) Final closure. (d) Preoperative marking. (e) Intraoperative. (f) Follow-up. 


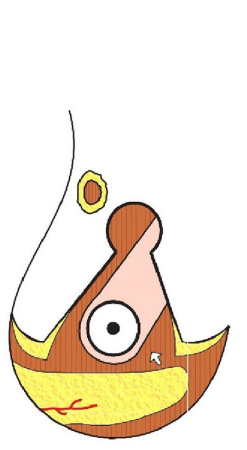

Fig $4 a$
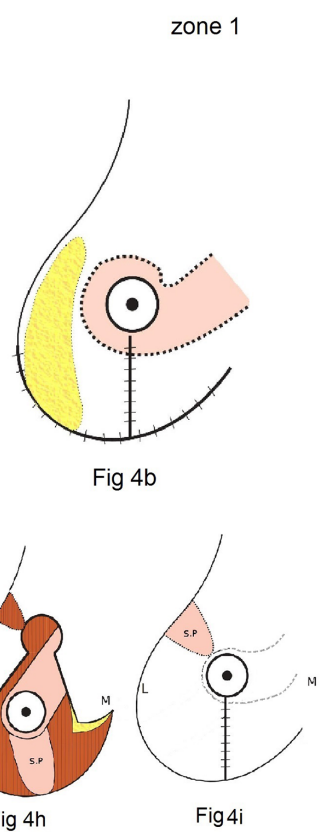
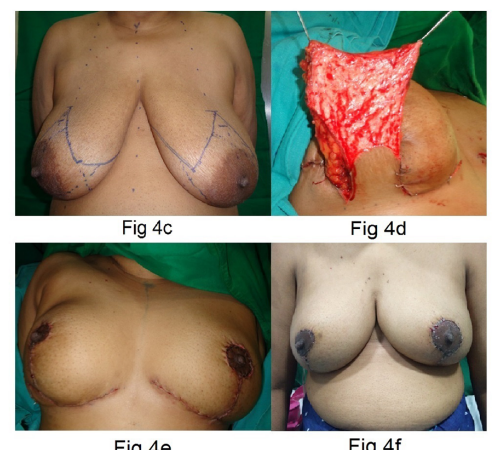

Fig $4 \mathrm{e}$

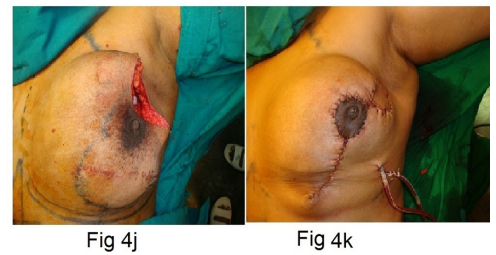

Fig. 4 Operative technique and clinical photographs for management of defects in zone 1. (a) Defect location and laterally based secondary dermoglandular pedicle. (b) Final closure. (c) Preoperative marking. (d) Secondary pedicle. (e) Final closure. (f) Follow-up. (g) Tumor in zone 1: extended skin island taken to replace the lost skin in zone 1. (h) Superomedial wise pattern planned with skin paddle. (i) The pedicle is rotated, so that the skin replaces the skin lost due to tumor excision. (j) Clinical photographs of patient showing the extended skin island to replace lost skin. (k) Extra skin taken with the pedicle to fill the defect.

vascularity of either. The problem in such a situation is that the NAC cannot be advanced in the defect created by the tumor, as it results in a very high and incorrect nipple-areola position.

The skin markings are done for the desired pedicle technique.

Difference in planning from routine reduction procedure is as follows:

The superomedial/inferior pedicle is deepithelialized and raised with an additional tissue attached to the pedicle which, after rotation/advancement of the pedicle, will lie exactly in the parenchymal defect. This additionally recruited tissue lies in the territory of the skin and parenchyma that will be excised in the standard Wise pattern excision. Thus, the tissue which is normally excised is utilized to fill the defect and maintain the shape and form of the breast. Rest of the excision is done as per the standard technique. The residual skin defect over the new NAC position can be closed primarily without much contour abnormality.

\section{Zone 3 (-Fig. 6 )}

The defect lies in the superomedial quadrant of the breast, so this pedicle is never an option; thus, either inferior pedicle or medial pedicle is planned.

The skin defect in most of the cases can be closed primarily. The Wise pattern design can be skewed, as shown in (-Fig. 6c,d) to balance the horizontal skin and soft-tissue excision.

\section{Zone 4 (-Fig. 7)}

These defects lie just lateral to the NAC. The superomedial pedicle is planned. This applies for defects that are not
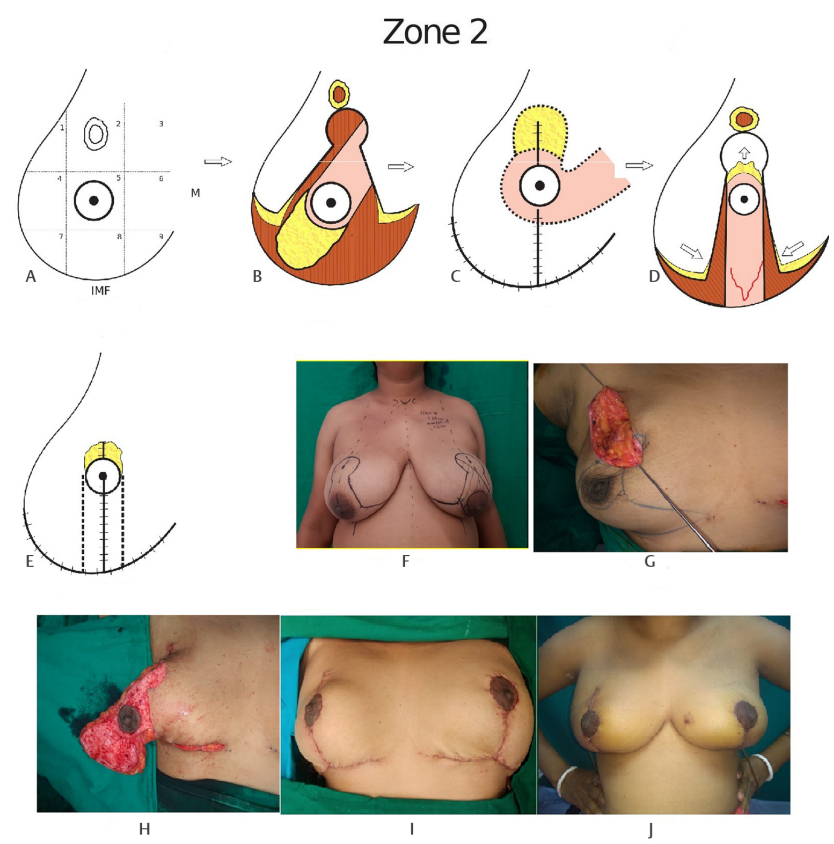

Fig. 5 Operative technique for management and clinical photographs of defects in zone 2. (a) Defect location. (b) Extended superomedial pedicle. (c) Final closure using the superomedial pedicle. (d) Extended Inferior pedicle. (e) Final closure using the inferior pedicle. (f) Preoperative marking. (g) Defect. (h) Extended superomedial pedicle. (i) Final closure. (j) Follow-up after 1 month.

close enough for the pedicle to reach (has intervening bridge of skin in between the pedicle and the defect). The defect was closed separately and then the rest of the oncoplastic procedure was performed. 
It is important to note that the excision is neither in the pedicle base nor a part of the normal excision. The lateral aspect of the breast has abundant tissue, and no

\section{Zone 3}
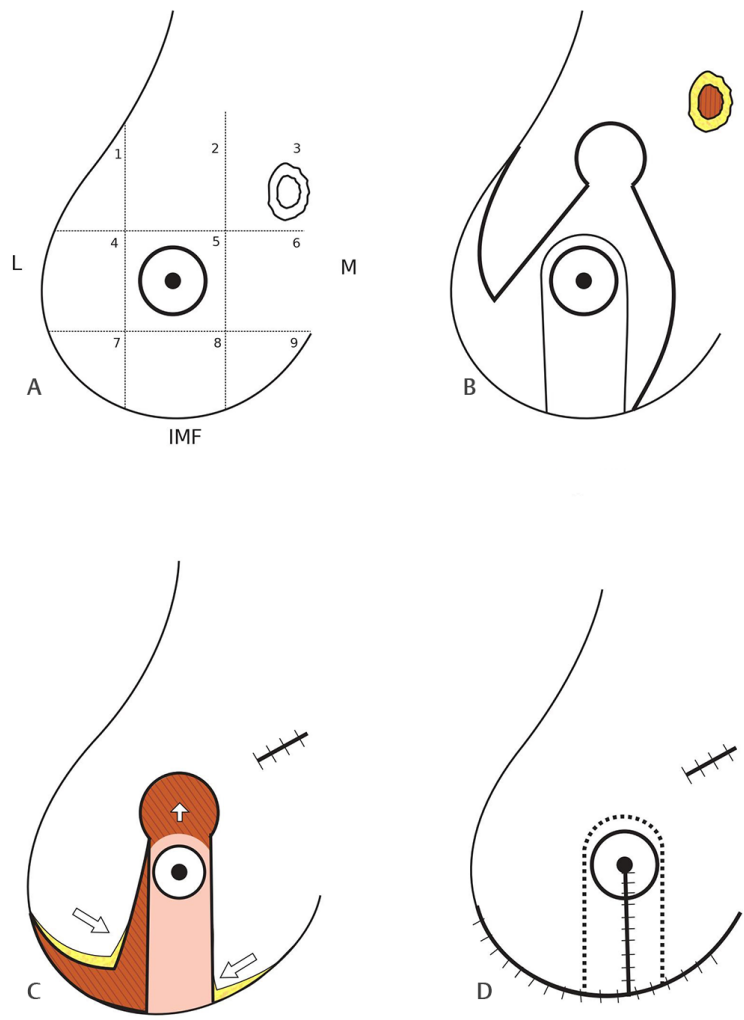

Fig. 6 Operative technique for management of defects in zone 3. (a) Defect location. (b) Planning of the inferior pedicle. (c) Skewed Wise pattern design (primary closure of the defect and balancing with opposite Wise pattern parenchymal excision). (d) Final closure. separate flap usually needs to be planned to give the breast contour.

However, if defect is large and primary closure is likely to cause contour abnormality, a laterally or inferolaterally based flap can be used to fill the defect, as described for zone 1.

\section{Zone 5 (-Fig. 8)}

Since it involves excision of NAC, the usual pedicle planning is not required. The aim here is to fill the defect in the central mound of the breast and provide a normal contour.

Planning is done like an inferior pedicle reduction mammoplasty technique. An inferiorly based dermoglandular flap is marked with a width of approximately $8 \mathrm{~cm}$ (as in inferior pedicle technique). This dermoglandular flap is based on the perforators from the anterior and posterior intercostal arteries.

A circular skin island of diameter equal to the diameter of the defect is marked at the distal-most part of this dermoglandular pedicle. The remaining part of this pedicle is deepithelialized. The dermoglandular pedicle is advanced to fill the defect in zone 5 of the breast.

The medial and lateral flaps are elevated, as in the Wise pattern parenchymal excision. Both these are rotated and sutured over the de-epithelialized inferior dermoglandular flap.

In moderate-sized breasts, when opposite breast reduction is not planned, Grisotti flap technique (-Fig. 9) can be used.

\section{Zone 6 (-Fig. 10)}

This zone lies medial to the NAC. The superomedial pedicle is only possible if the excision is at the medial aspect of zone 6 , but the superomedial pedicle is not possible if the excision is on the lateral aspect of zone 6 , as the excision cuts through the base of the pedicle carrying the NAC.

Zone 4
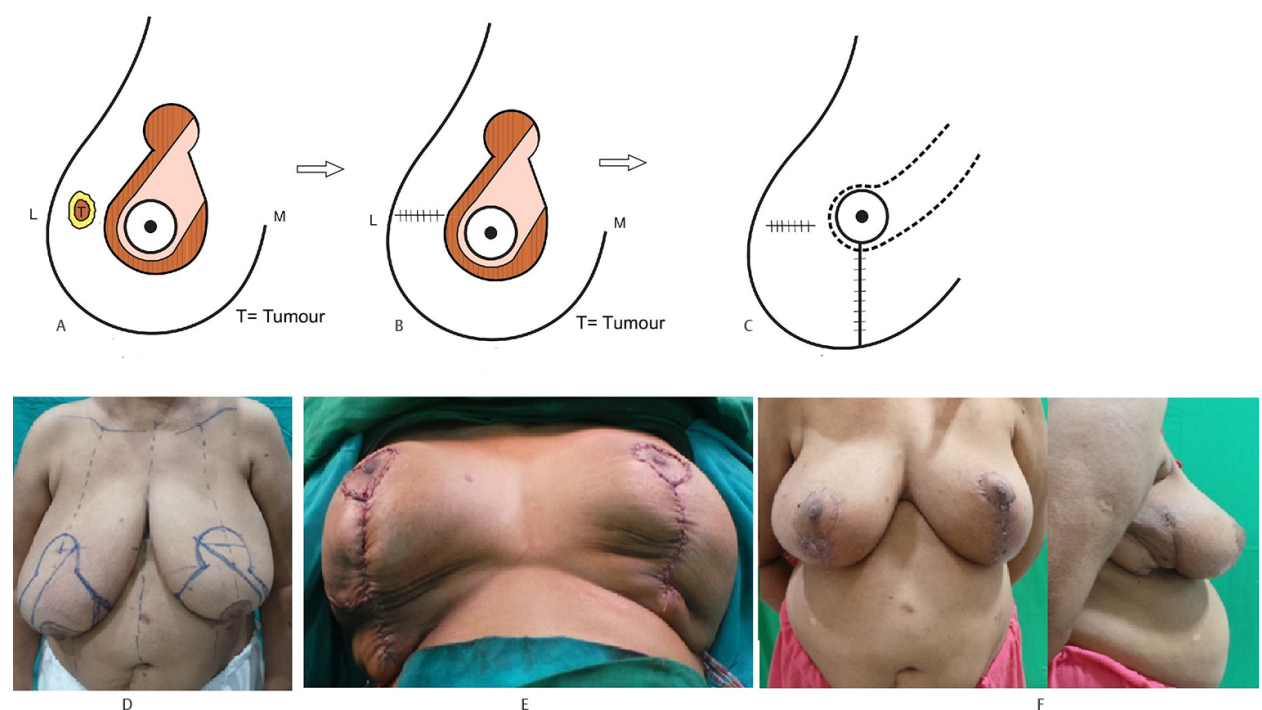

Fig. 7 Operative technique and clinical photographs for management of defects in zone 4 ( $T=$ tumor). (a) Tumor in zone 4 . (b) Tumor removed and skin defect closed primarily (c) Reduction mammoplasty performed. (d) Preoperative marking. (e) Final closure. (f) Follow-up. 


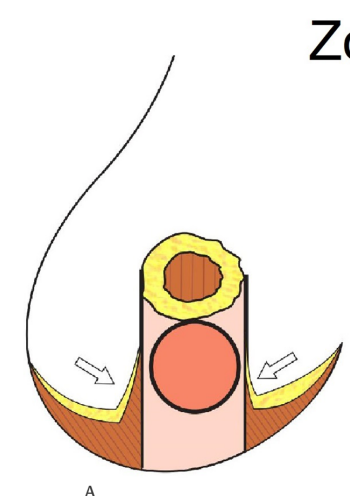

Zone 5
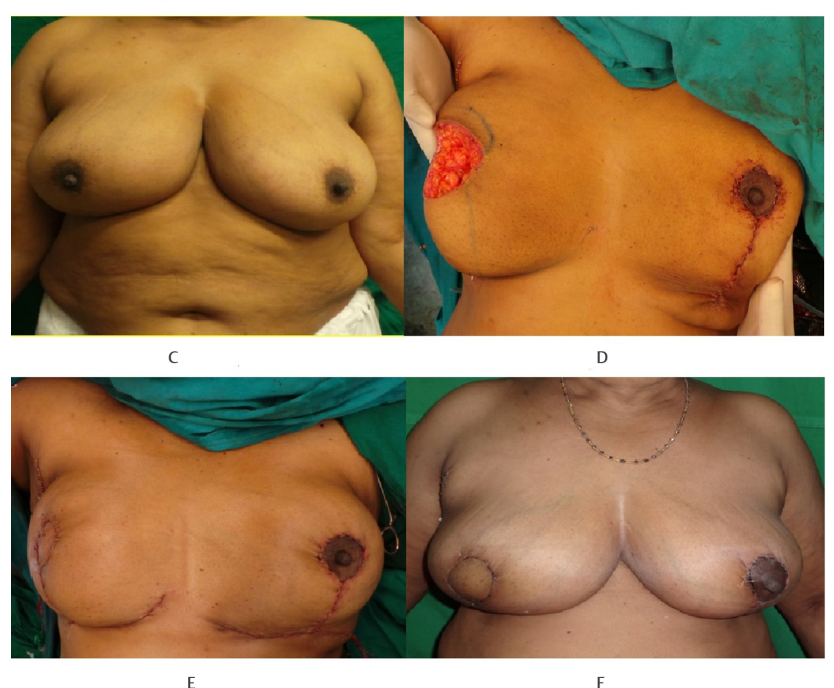

Fig. 8 Operative technique and clinical photographs for management of defects in zone 5. (a) Defect location and inferiorly based dermoglandular flap with preserved skin island. (b) Final closure. (c) Preoperative. (d) Intraoperative defect. (e) Final closure. (f) Follow-up after 1 month.
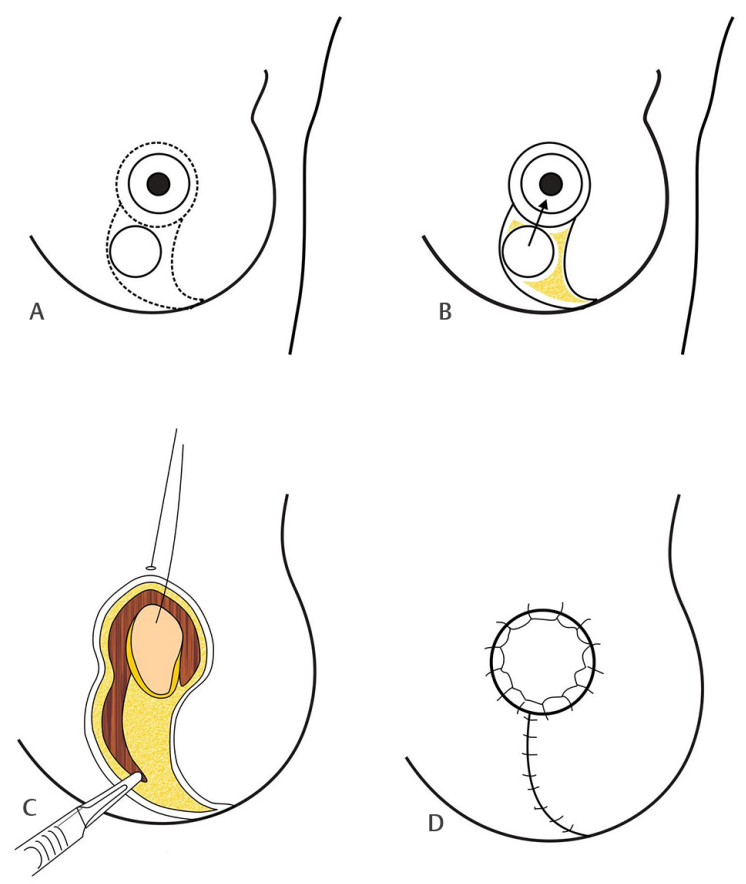

Fig. 9 Grisotti flap technique for management of zone 5.

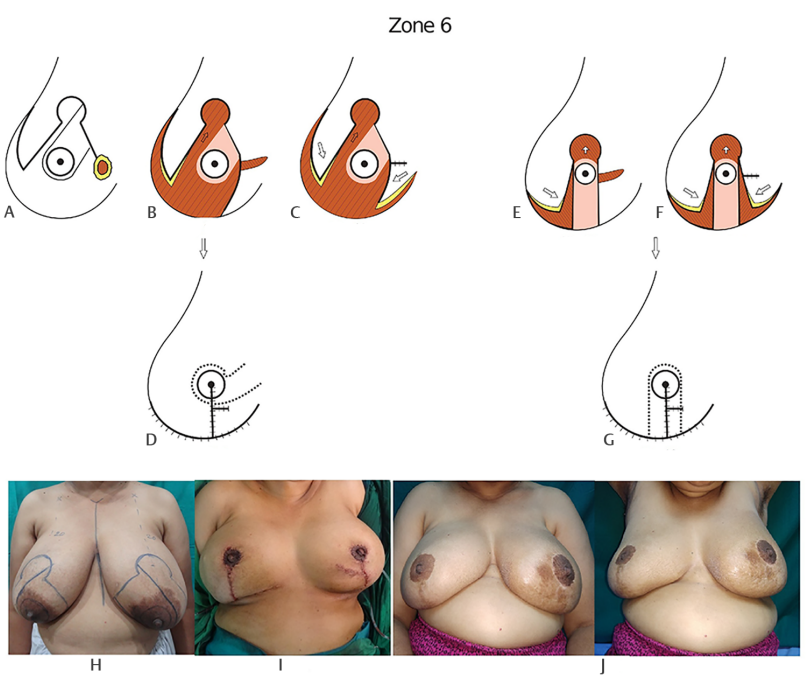

Fig. 10 Operative technique and clinical photographs for management of defects in zone 6. (a) Defect location and planning of the superomedial pedicle. (b) Superomedial pedicle with defect. (c) Superomedial pedicle with primary closure of the defect and balancing with opposite Wise pattern parenchymal excision. (d) Final closure. (e) Inferior pedicle with defect. (f) Inferior pedicle with primary closure of the defect and balancing with opposite Wise pattern parenchymal excision. (g) Final closure. (h) Preoperative marking. (i) Final closure. (j) Follow-up after 1 month.

The preferred is the inferior pedicle in zone 6 . The tumor, thus, lies at a location that is neither the base of the pedicle nor the routine excision area of the reduction mammoplasty. The skin and soft-tissue defect, thus, has to be addressed by closing it separately in a transverse fashion.

The transverse limb of the Wise pattern may need adjustment by giving a horizontal incision at the inframammary fold (skewed Wise pattern) to balance the opposite limb.

\section{Results}

Of the 61 cases included in this paper, there were 32 cases with left-sided carcinoma, 27 with right-sided carcinoma, and two cases with bilateral carcinoma breast. Thus, there were 63 oncoplastic breast reduction mammoplasties done. Twenty-two cases were located in zone 1 , nine cases in zone 2 , seven cases in zone 3 , three cases in zone 4 , four cases in zone 5 , one case in zone 6,12 cases in zone 7 , two cases in zone 8 , and three cases in zone 9.

The most common pedicle used for oncoplastic breast reduction was superomedial in 38 (60.31\%) cases, followed by inferior in 19 (30.15\%) cases and medial in six cases (9. $52 \%)$. The minimum weight of the tissue excised was $160 \mathrm{~g}$ and the maximum was $1950 \mathrm{~g}$ with a median of $445 \mathrm{~g}$. Vertical short scar technique was used in 33 (52.38\%) cases and the Wise pattern skin incision was used in 30 (47.61\%) cases.

In the normal side breast reductions, the superomedial pedicle was used in 52 cases (88.13\%), followed by inferior pedicle in seven cases (11.86\%). The minimum weight of the tissue excised in the normal breast was $140 \mathrm{~g}$ and the 
maximum was $1750 \mathrm{~g}$ with a median of $452 \mathrm{~g}$. All patients were satisfied with their cosmetic outcome.

Follow-up period ranged from 4 months to 65 months with a mean of 31 months.

Local tumor recurrence was observed in one $(1.63 \%)$ and distant metastasis in two (3.27\%) of our patients on follow-up.

\section{Complications}

Four (6.55\%) patients had partial skin necrosis, and three (4.91\%) had suture line dehiscence requiring secondary suturing (Clavien-Dindo Grade IIIa).

Two (3.27\%) patients had wound infection, eight (13.11\%) patients had partial fat necrosis, and one (1.63\%) had seroma (Clavien-Dindo Grade I).

\section{Discussion}

The two important considerations for breast aesthesis are good contour and correct nipple-areola position. Both can be achieved using the principles of breast reduction techniques, keeping in mind the prerequisite of a moderate-sized breast and a small enough excision to enable tissue readjustments.

It is observed that up to $10 \%$ of breast tissue can be removed without notable breast deformities, as described by Cochrane et al. ${ }^{6}$

Delay and Clough demonstrated that when up to $20 \%$ of breast volume is removed, local parenchymal rearrangement is sufficient to obtain satisfactory results. ${ }^{7}$

Oncoplastic techniques have been in use for approximately two decades but is gaining popularity now. The reason can be attributed to the increasing incidence of breast cancer in younger patients between 30 to 50 years of age; hence, more demand for breast reconstruction with good aesthetic outcome. ${ }^{8}$

Furthermore, for achieving symmetry, the opposite side breast reduction surgery can be done at the same time, which reduces the number of surgical procedures performed on the patients. As radiation therapy changes the shape of the breast, the symmetrization procedure can also be performed as a secondary procedure. Fitoussi et al recommended delayed contralateral symmetrizing procedure in his series of 540 patients. ${ }^{9}$ Various studies have shown safety and better aesthetic outcomes with immediate reconstruction as well. ${ }^{10,11}$

In all of our cases, preoperative planning of the skin incision and pedicle selection was done in collaboration with the breast surgeon.

There can be two main case scenarios, one where the tumor lies within the region of parenchymal excision and the other where the tumor lies outside this region. In the first scenario, as is implied, there is no modification required in the standard reduction mammoplasty technique. However, in the latter scenario, modification of technique is imperative and may employ the use of either extended or secondary pedicles. Since most cancers are located in the upper aspect of the breast, modification of the standard technique was required in most of our cases.

The most common pedicle used in our patients was the superomedial pedicle, followed by the inferior pedicle. Although both types of pedicles can be used for certain defects, the superomedial pedicle was used more often, as it is preferred by most of the surgeons.

Our experience echoes the various advantages of oncoplastic breast reduction that have been noted in other studies. In breast oncoplasty, the resection margins are not compromised, as a significant amount of glandular tissue has to be eventually removed. ${ }^{12,13}$ Also, the resultant smaller breast size is postulated to improve the efficacy of radiation therapy, due to uniform distribution and lesser dose. Gray et al in a series of 257 patients reported more retraction and asymmetry in women with large breasts as against women with small breasts. ${ }^{14}$ Also, Moody et al found that a greater number of patients (39\%) with large breasts experienced late radiation changes as compared with patients with small breasts (6\%). ${ }^{15}$ Losken et al noted that simultaneous reduction of the contralateral breast theoretically reduces the additional risk of breast cancer through the removal of excess breast parenchyma. ${ }^{16}$ Rate of incidentally discovered cancer in the contralateral symmetrizing reduction specimens ranges from 4.6 to $11 \% .^{17,18}$

Kronowitz reported a complication rate for oncoplastic bilateral breast reduction between $17 \%$ and $24 \%{ }^{19}$ In our series, the overall flap related complication rate was $22.9 \%$ (14 patients). Partial skin necrosis in four, suture line dehiscence in three, infection in two, seroma in one, and fat necrosis in eight.

Fat necrosis is difficult to distinguish from recurrence in the postoperative period, as both present as a lump which is firm-to-hard on palpation. In three of our patients, we had to rule out recurrence by performing a biopsy of the lump. All oncoplastic surgeries involve modified extended and secondary pedicles as well as mobilization of the breast parenchyma, which may be the reason for a small amount of fat necrosis. All our cases were managed conservatively.

Local tumor recurrence was observed in $1(1.63 \%)$ and distant metastasis in 2 (3.27\%) of our patients on follow-up. Local recurrence rate of $6.8 \%$ was observed by Fitoussi et al in their study of 540 patients who underwent oncoplastic breast surgery. ${ }^{9}$ These results are comparable to patients undergoing standard BCT alone. Similarly, Rietjens reported a recurrence rate of $3 \% .^{20}$

\section{Conclusions}

Breast oncoplastic techniques are effective, reliable, oncologically safe, and conducted with minimal complications in patients with moderately large ptotic breasts. It is also possible to make planning easier and more reproducible by following the reconstruction procedures as described in the article.

We believe that these techniques should be incorporated in the armamentarium of every plastic surgeon to manage the defect, which is created after breast conservation surgery, in order to achieve the best cosmetic outcomes. 


\section{Source(s) of Support}

Nil.

\section{Conflicting of Interest \\ None declared.}

\section{Acknowledgment}

Mr. Nilesh Ganthade, Medical Graphics Department, Tata Memorial Hospital, Mumbai.

\section{References}

1 Malvia S, Bagadi SA, Dubey US, Saxena S. Epidemiology of breast cancer in Indian women. Asia Pac J Clin Oncol 2017;13(4):289-295

2 Blichert-Toft M, Nielsen M, Düring M, et al. Long-term results of breast conserving surgery vs. mastectomy for early stage invasive breast cancer: 20-year follow-up of the Danish randomized DBCG-82TM protocol. Acta Oncol 2008;47(4):672-681

3 Piper ML, Esserman LJ, Sbitany H, Peled AW. Outcomes following oncoplastic reduction mammoplasty: a systematic review. Ann Plast Surg 2016;76(Suppl 3) :S222-S226

4 Schwartz JD. New approach to oncoplastic breast conservation: combining autologous volume replacement and the wise-pattern mammaplasty. Plast Reconstr Surg Glob Open 2018;6(10):e1987

5 Kronowitz SJ, Kuerer HM, Buchholz TA, Valero V, Hunt KK. A management algorithm and practical oncoplastic surgical techniques for repairing partial mastectomy defects. Plast Reconstr Surg 2008;122(6):1631-1647

6 Cochrane RA, Valasiadou P, Wilson ARM, Al-Ghazal SK, Macmillan RD. Cosmesis and satisfaction after breast-conserving surgery correlates with the percentage of breast volume excised. Br J Surg 2003;90(12):1505-1509

7 Delay E, Clough KB. [Oncoplastic breast surgery: conclusions and future perspectives]. Ann Chir Plast Esthet 2008;53(2):226-227

8 Chopra B, Kaur V, Singh K, et al. Age shift: breast cancer is occurring in younger age groups-is it true? Clin Cancer Investig J 2014;3:526-529
9 Fitoussi AD, Berry MG, Famà F, et al. Oncoplastic breast surgery for cancer: analysis of 540 consecutive cases [outcomes article]. Plast Reconstr Surg 2010;125(2):454-462

10 Clough KB, Kroll SS, Audretsch W. An approach to the repair of partial mastectomy defects. Plast Reconstr Surg 1999;104(2):409-420

11 Spear SL, Burke JB, Forman D, Zuurbier RA, Berg CD. Experience with reduction mammaplasty following breast conservation surgery and radiation therapy. Plast Reconstr Surg 1998;102(6):1913-1916

12 Giacalone PL, Roger P, Dubon O, et al. Comparative study of the accuracy of breast resection in oncoplastic surgery and quadrantectomy in breast cancer. Ann Surg Oncol 2007;14(2):605-614

13 Kaur N, Petit JY, Rietjens M, et al. Comparative study of surgical margins in oncoplastic surgery and quadrantectomy in breast cancer. Ann Surg Oncol 2005;12(7):539-545

14 Gray JR, McCormick B, Cox L, Yahalom J. Primary breast irradiation in large-breasted or heavy women: analysis of cosmetic outcome. Int J Radiat Oncol Biol Phys 1991;21(2):347-354

15 Moody AM, Mayles WP, Bliss JM, et al. The influence of breast size on late radiation effects and association with radiotherapy dose inhomogeneity. Radiother Oncol 1994;33(2):106-112

16 Losken A, Styblo TM, Carlson GW, Jones GE, Amerson BJ. Management algorithm and outcome evaluation of partial mastectomy defects treated using reduction or mastopexy techniques. Ann Plast Surg 2007;59(3):235-242

17 Petit JY, Rietjens M, Contesso G, Bertin F, Gilles R. Contralateral mastoplasty for breast reconstruction: a good opportunity for glandular exploration and occult carcinomas diagnosis. Ann Surg Oncol 1997;4(6):511-515

18 Smith BL, Bertagnolli M, Klein BB, et al. Evaluation of the contralateral breast. The role of biopsy at the time of treatment of primary breast cancer. Ann Surg 1992;216(1):17-21

19 Kronowitz SJ, Hunt KK, Kuerer HM, et al. Practical guidelines for repair of partial mastectomy defects using the breast reduction technique in patients undergoing breast conservation therapy. Plast Reconstr Surg 2007;120(7):1755-1768

20 Rietjens M, Urban CA, Rey PC, et al. Long-term oncological results of breast conservative treatment with oncoplastic surgery. Breast 2007;16(4):387-395 